\title{
Optimization of the single point incremental forming process for titanium sheets by using response surface
}

\author{
Badreddine Saidi ${ }^{1,2 *}$, Laurence Giraud-Moreau ${ }^{1}$, Abel Cherouat ${ }^{1}$ \\ ${ }^{1}$ Université de Technologie de Troyes France-GAMMA3, France \\ ${ }^{2}$ Ecole Nationale d'Ingénieurs de Tunis-MAI Tunisia
}

\begin{abstract}
The single point incremental forming process is well-known to be perfectly suited for prototyping and small series. One of its fields of applicability is the medicine area for the forming of titanium prostheses or titanium medical implants. However this process is not yet very industrialized, mainly due its geometrical inaccuracy, its not homogeneous thickness distribution... Moreover considerable forces can occur. They must be controlled in order to preserve the tooling. In this paper, a numerical approach is proposed in order to minimize the maximum force achieved during the incremental forming of titanium sheets and to maximize the minimal thickness. A surface response methodology is used to find the optimal values of two input parameters of the process, the punch diameter and the vertical step size of the tool path.
\end{abstract}

\section{Introduction}

The single point incremental forming process (ISF) is an emerging process with a high industrial interest. This process is based on the use of a spherical tool, which is moved along CNC controlled tool path (figure 1). During the incremental forming process, the sheet blank is fixed in sheet holder. The tool follows a certain tool path and progressively deforms the sheet. Because incremental forming is a dieless process, it is perfectly suited for prototyping and small volume production $[1,2]$.

Medical implants are one of the potential fields of application of the incremental forming process, due to the need of product customization to each patient. One of the major advantages of the ISF process is the ability to program several punch trajectories on the same machine in order to obtain different shapes perfectly suited to each patient. Titanium alloys are generally used by the biomedical industries because of their corrosive resistance and great biocompatibility with the human body. Titanium is recognized by its high strength-toweight ratio. But its high cost and difficult formability compared with aluminum make that the incremental forming of titanium sheet is little studied. Before the incremental forming process of titanium sheets is really industrialized, studies are necessary. The ISF process indeed suffers from a big slowness, geometrical inaccuracy, a not homogeneous thickness distribution which reduces its industrial suitability $[1,3,4,5]$.

During this process, considerable forces can occur [5]. The control of the forming force is particularly important when titanium sheets are used to ensure the safe use of a $\mathrm{CNC}$ milling machine and preserve the tooling and machinery $[5,6]$.

The aim of this paper is to determine input parameters of the process in order to minimize the maximum force achieved during the incremental forming of titanium sheets and to optimize the thickness reduction. Several studies were developed to optimize the incremental forming of aluminum sheets $[2,8]$. A little less was done for titanium sheets.

In this paper, a numerical procedure is developed in order to study the influence of two input parameters, the punch diameter and the vertical step on the forming force and the minimal thickness. To conduct this study, an experimental design combined to response surface methodology is used [2]. The experimental design is based on finite element analysis realized with ABAQUS/Explicit. Mathematical relations are defined from the response surfaces to predict the forming force and the thinning rate as function of the two input parameters and to define the input parameters allowing to maximize the forming force and maximize the minimal thickness.

\section{Incremental forming of titanium sheets}

The single point incremental sheet forming (SPIF) process is illustrated on the figure 1. Different trajectories along which the tool moves have been studied in the literature. The tool path most frequently used and that the

\footnotetext{
${ }^{\mathrm{a}}$ Corresponding author: laurence.moreau@utt.fr
} 
authors of the paper have already studied during experimental works [3] is composed of rotational movements in the horizontal plane combined with small steps in the vertical direction (see figure 2). This tool path is used in this study.

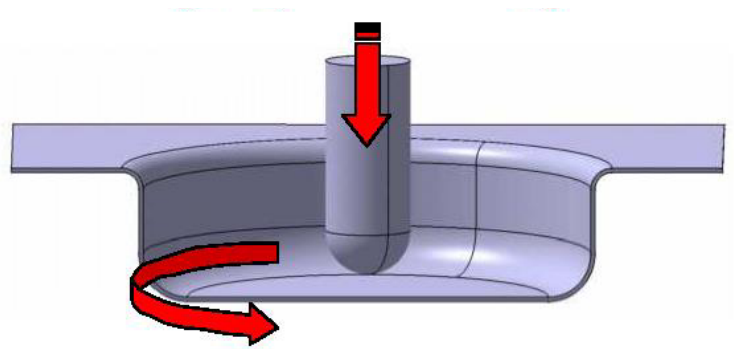

Figure 1. Incremental forming process.

This paper concerns the incremental forming of titanium ASTM grade 2 sheets with a thickness of 0.5 $\mathrm{mm}$. A truncated cone with a wall angle of $60^{\circ}$, a maximum diameter of $100 \mathrm{~mm}$ and a depth of $20 \mathrm{~mm}$ was chosen for this preliminary study about the optimization of the incremental forming process with titanium sheets. The sheet has a size of $300 \mathrm{~mm} \mathrm{x}$ $300 \mathrm{~mm}$.

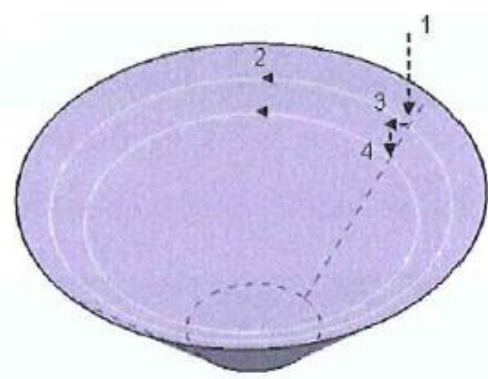

Figure 2. Tool path.

\section{Numerical simulation}

During the incremental forming process, the sheet is held firmly by the clamping system so that there is no slipping. A full model of blank holder modeled by rigid surfaces has been chosen to represent the experimental clamping system. A vertical pressure of 4.3MPA [9] has been applied. Figure 3 presents the numerical model at the beginning of the process. The initial and final mesh of the sheet for a punch diameter of $10 \mathrm{~mm}$ and a step size of $1 \mathrm{~mm}$ is shown on figure 4 .

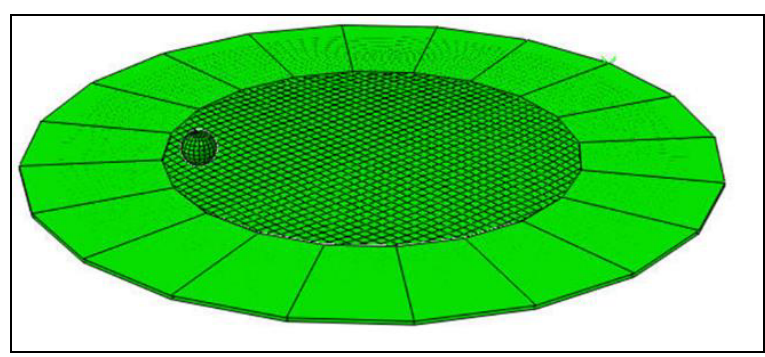

Figure 3. Numerical model.

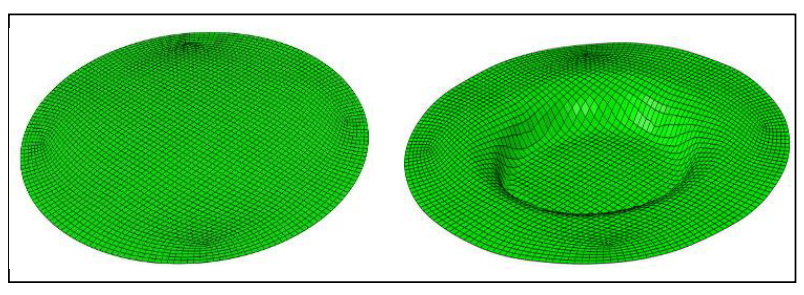

Figure 4. Initial and final mesh of the sheet.

In what concerns material modeling, an elasto-plastic model was chosen for the simulation. The titanium behavior was modeled by means of a Swift type hardening law :

$$
\sigma=k\left(\varepsilon_{0}+\varepsilon_{p}\right)^{\mathrm{n}}
$$

A tensile test allowed generating the strain-stress curve for the titanium sheet. Figure 5 presents this stressstrain curve.

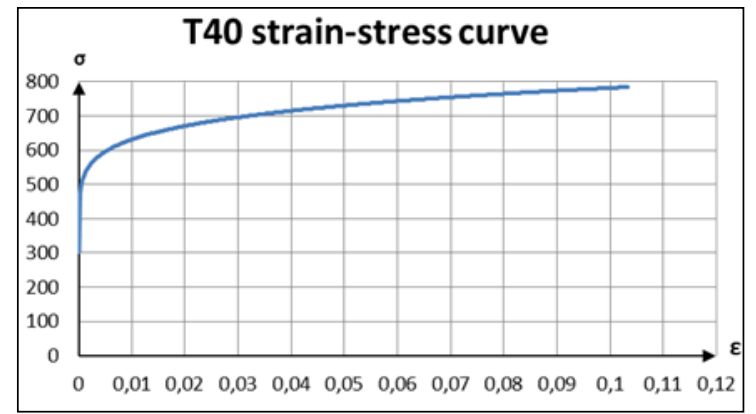

Figure 5. Stress-strain curve.

An inverse analysis using the data from this tensile test has been used to identify the mechanical parameters. Table 1 summarizes the mechanical properties of the material obtained thanks to the inverse method.

Table 1. Mechanical properties of the Titanium grade 2.

\begin{tabular}{|l|l|}
\hline Modulus of elasticity $: \boldsymbol{E}$ & $100 \mathrm{Gpa}$ \\
\hline Yield strength: $\boldsymbol{\sigma}$ & $210 \mathrm{Mpa}$ \\
\hline Hardening coefficient: $\boldsymbol{n}$ & 0.084 \\
\hline Coefficient of proportionality: $\boldsymbol{K}$ & $697,7 \mathrm{MPa}$ \\
\hline Strain $: \boldsymbol{\varepsilon}_{\boldsymbol{0}}$ & 0.00157 \\
\hline
\end{tabular}

\section{Experimental design}

The goal of this present study is to determine the values of the punch diameter $(\mathrm{dp})$, and the vertical step size $(\Delta \mathrm{z})$ which allow to minimize the forming force and maximize the minimal thickness. As the number of input variables is low, a full factorial design at three levels has been chosen to realize the experimental design. Table 2 presents the forming factors and their respected levels.

The numerical simulation of the incremental forming process has been performed with the ABAQUS explicit solver. The finite elements chosen to mesh the sheet are shell elements S4R with 4 nodes and reduced integration. The spherical tool is modeled by a rigid surface. 
Table 2. Forming factors and levels.

\begin{tabular}{|l|c|c|c|c|}
\hline Factors & $\begin{array}{c}\text { Factor } \\
\text { notation }\end{array}$ & $\begin{array}{c}\text { Level } \\
1\end{array}$ & $\begin{array}{c}\text { Level } \\
2\end{array}$ & $\begin{array}{c}\text { Level } \\
3\end{array}$ \\
\hline $\begin{array}{l}\text { dp : Tool } \\
\text { diameter }(\mathrm{mm})\end{array}$ & $\mathrm{A}$ & 10 & 12.5 & 15 \\
\hline $\begin{array}{l}\Delta \mathrm{z}: \text { Step size } \\
(\mathrm{mm})\end{array}$ & $\mathrm{B}$ & 0.5 & 0.75 & 1 \\
\hline
\end{tabular}

Nine numerical simulations of the forming process were carried out. The responses values are the minimal thinning and maximal forming force. Table 3 presents the numerical results performed according to the full factorial design.

Table 3. Numerical results.

\begin{tabular}{|c|c|c|c|c|}
\hline $\mathbf{n}^{\mathbf{0}}$ & $\begin{array}{c}\mathbf{D p} \\
\mathbf{( m m})\end{array}$ & $\begin{array}{c}\mathbf{\Delta z} \\
\mathbf{( m m})\end{array}$ & $\begin{array}{c}\text { Minimal } \\
\text { thickness } \\
\mathbf{( m m})\end{array}$ & $\begin{array}{c}\text { Maximal } \\
\text { forming force } \\
\mathbf{( N )}\end{array}$ \\
\hline 1 & 10 & 0.5 & 0,255909 & 870 \\
\hline 2 & 10 & 0.75 & 0,222006 & 950 \\
\hline 3 & 10 & 1 & 0,172874 & 1030 \\
\hline 4 & 12.5 & 0.5 & 0,258584 & 920 \\
\hline 5 & 12.5 & 0.75 & 0,106811 & 980 \\
\hline 6 & 12.5 & 1 & 0,197069 & 1110 \\
\hline 7 & 15 & 0.5 & 0,205474 & 1060 \\
\hline 8 & 15 & 0.75 & 0,205505 & 1120 \\
\hline 9 & 15 & 1 & 0,274236 & 1180 \\
\hline
\end{tabular}

\section{Optimization results}

A quadratic polynomial equation has been considered in order to fit the numerical results and get a relationship between the response values and the input parameters.

The two polynomial models (2) and (3) of second degree considered for the forming force and minimal thickness are the following [10]:

$$
\begin{aligned}
& \mathrm{F}_{\max }=a_{0}+a_{1} d_{p}+a_{2} \Delta z+a_{3} d_{p}^{2}+a_{4} d_{p} \Delta z+a_{5} \Delta z^{2} \\
& \mathrm{STH}=b_{0}+b_{1} d_{p}+b_{2} \Delta z+b_{3} d_{p}^{2}+b_{4} d_{p} \Delta z+b_{5} \Delta z^{2}
\end{aligned}
$$

Table 4 presents the values of the coefficients, which allow to predict the forming force and the thinning rate according to the two input parameters. These numerical results have been obtained with ANOVA.

Table 4. Coefficients of the fit functions.

\begin{tabular}{|c|c|c|c|c|c|}
\hline $\boldsymbol{a}_{\mathbf{0}}$ & $\boldsymbol{a}_{\mathbf{1}}$ & $\boldsymbol{a}_{\mathbf{2}}$ & $\boldsymbol{a}_{\mathbf{3}}$ & $\boldsymbol{a}_{\mathbf{4}}$ & $\boldsymbol{a}_{\mathbf{5}}$ \\
\hline 1082,2 & $-80,7$ & 233,3 & 5,1 & $-16,0$ & 186,7 \\
\hline $\boldsymbol{b}_{\mathbf{0}}$ & $\boldsymbol{b}_{\mathbf{1}}$ & $\boldsymbol{b}_{\mathbf{2}}$ & $\boldsymbol{b}_{\mathbf{3}}$ & $\boldsymbol{b}_{\mathbf{4}}$ & $\boldsymbol{b}_{\mathbf{5}}$ \\
\hline 1,48 & $-0,12$ & $-1,40$ & 0,0037 & 0,03 & 0,6 \\
\hline
\end{tabular}

The 3D response surfaces showing the variations of the forming force and the minimal thickness with respect to the punch diameter and the step size are given in figure 6 and 7. These surfaces are useful to understand the interaction properties between both the punch diameter and step size and the output parameters. We can see on these figures that the increase of the tool diameter and the step size induces an increase of force forming. As regards the minimal thickness, a nonlinear response is observed. The maximal thickness for the considered input parameters is obtained for the minimal tool diameter and minimal step size.

These response surfaces have been used to determine the optimal values of the tool diameter and the vertical step size which allow to minimize the forming force and maximize the minimal thickness. The results are presented in the table 5 .

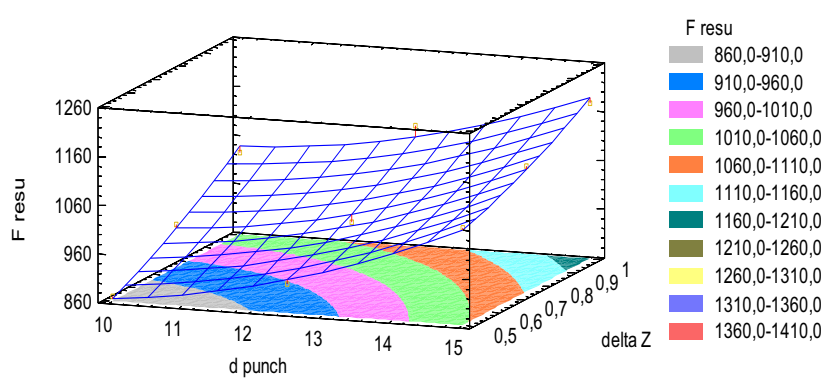

Figure 6. Response surface associated to the forming force.

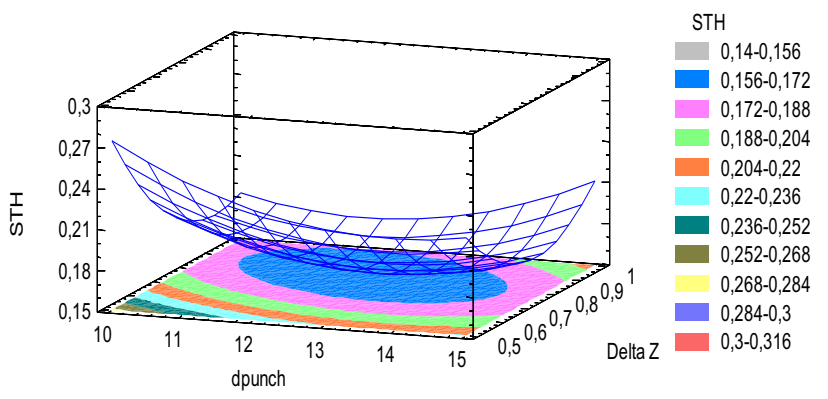

Figure 7. Response surface associated to the minimal thickness.

Table 5. Coefficients of the fit functions.

\begin{tabular}{|l|l|l|l|}
\hline Factor & Low & High & Optimum \\
\hline$d p(\mathrm{~mm})$ & 10,0 & 15,0 & 10,0 \\
\hline$\Delta z(\mathrm{~mm})$ & 0,5 & 1,0 & 0,5 \\
\hline \multicolumn{3}{|r|}{ STH $\max (\mathbf{m m})$} & 0,273923 \\
\hline \multicolumn{3}{|r|}{ Fres $\min (\mathbf{N})$} & 865,556 \\
\hline
\end{tabular}

An analysis of variance was conducted with ANOVA in order to analyze the effects of the input parameters on the value of the forming force and minimal thickness. They are presented in figures 8 and 9 .

A quasi linear effect of the punch diameter and the step size on the forming force is observed. Figure 9 shows a quadratic effect of the input parameters on the thickness response. Figures 10 and 11 presenting the standardized PARETO chart show that the punch diameter and the vertical step size have a similar effect on the forming force but the vertical step size has a more important effect than the punch diameter on the thickness. 


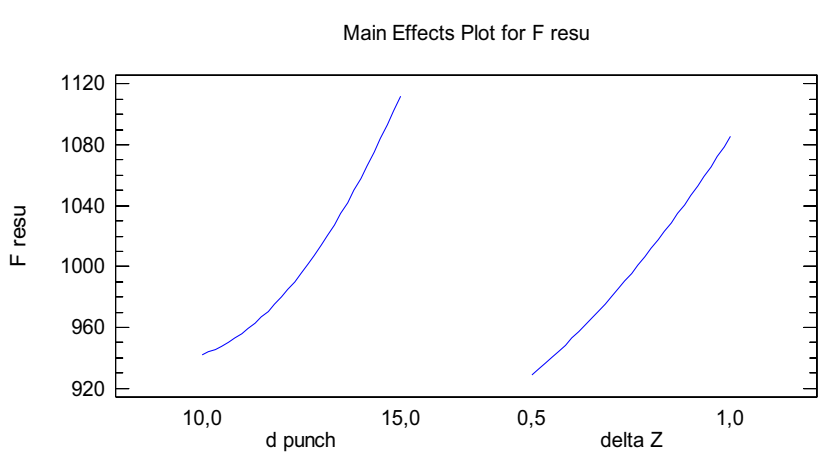

Figure 8. Effects of the input parameters on the value of the forming force.

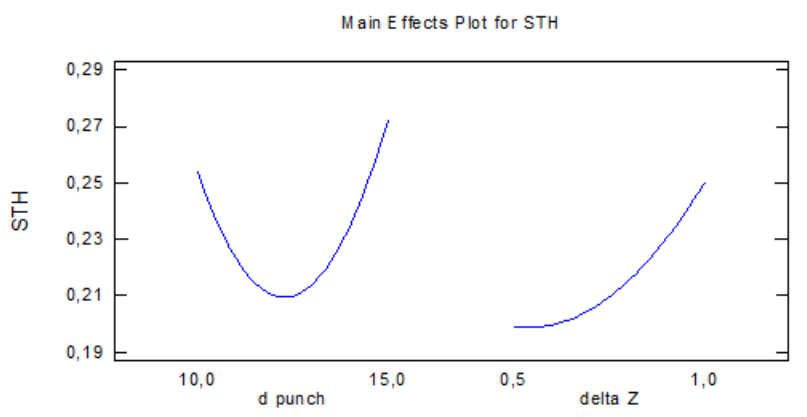

Figure 9. Effects of the input parameters on the value of minimal thickness.

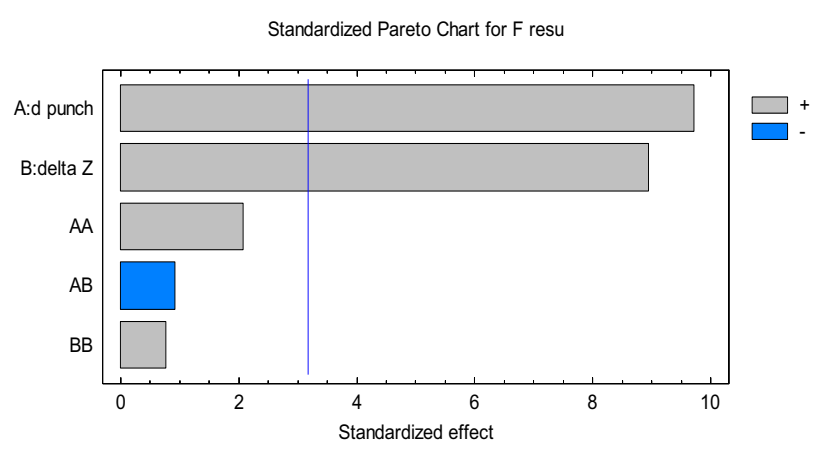

Figure 10. Standardized PARETO chart for force forming.

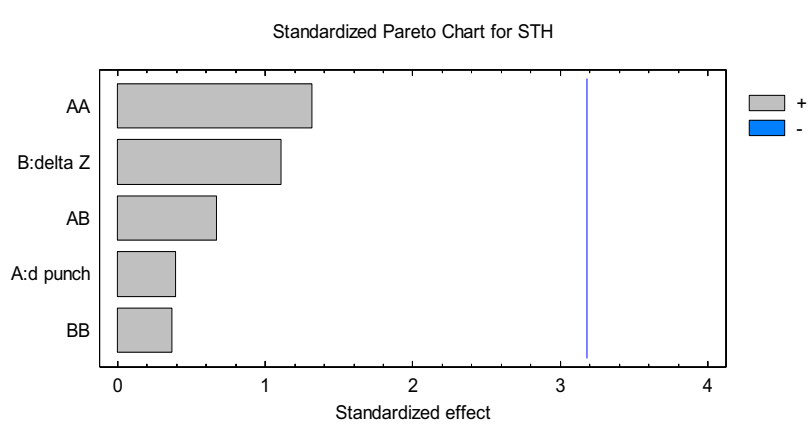

Figure 11. Standardized PARETO chart for the thickness.

Figures 12 and 13 present the normal probability plot. The process parameters are considered significance to the experiment as there is a large angled slope of the straight line. We can see that all the points are relatively close to the straight line and thus that the data follow a normal distribution [8].

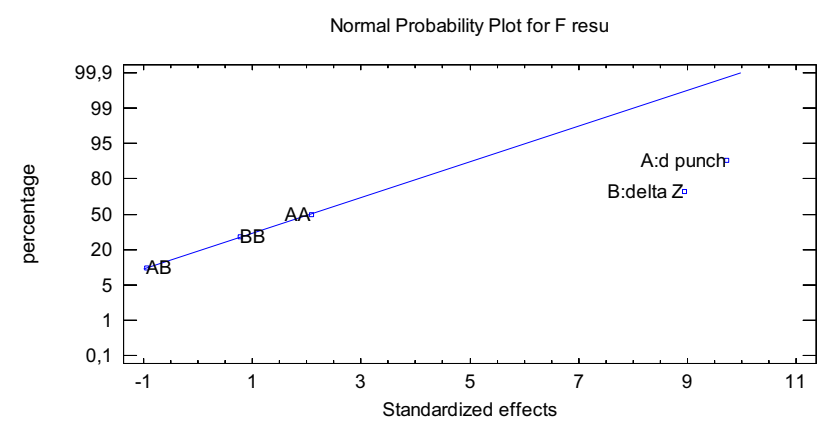

Figure 12. Normal probability distribution for force forming.

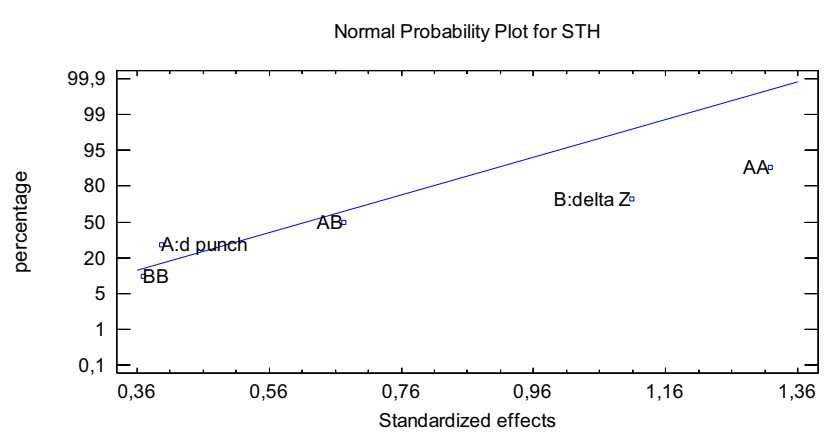

Figure 13. Normal probability distribution for thickness.

\section{Conclusion}

In this paper, a numerical approach based on finite element analysis and response surface methodology has been applied to optimize the incremental forming process of titanium sheets. A second-order quadratic function has been defined in order to predict the maximal forming force and minimal thickness as function of the punch diameter and the vertical step size.

The impact of the punch diameter and the vertical step size on the maximal forming force and minimal thickness has been studied.

The optimal values of the input parameters allowing minimizing the forming force and maximizing the minimal thickness have been defined from the response surfaces.

This study about the optimization of the incremental forming process with titanium sheets is a preliminary study. Only two input parameters were considered and the material low used in the finite element model doesn't take into account the general anisotropy. This study will be pursued in future works.

\section{References}

1. G.Ambrogio, I. Corstantino, L. De Napoli, L. Filice, L. Fratini, M. Muzzupappa, J. of Materials Proc. Technol., 1153-154, p. 501-507, (2004) 
2. V. Gulati, A. Aryal, P. Katyal, A. Goswami, J.1 of The Institution of Engineers (India): Series C, (2015)

3. L. Giraud-Moreau, A. Cherouat, A. Merat IDDRG 2014, (2014)

4. J. Duflou, Y. Tunckol,A. Szekeres, P. Vanherck, J. of Mat. Proc. Technol. , 1189, p. 65-72, (2007)

5. R. Aerens, P. Eyckens, A. Van Bael, J. R. Duflou, Int. J. Adv. Manuf. Technol., (2009)

6. L. Giraud-Moreau, A. Cherouat, J. Zhang, H. Borouchaki, Key Engin. Mater., 554-557, pp 13751381, (2013)

7. B. Saidi, A. Boulila, A. Mahfoubh, N. Rachid, Mechanics \& Industry, 16, $\mathrm{n}^{\circ}$ 1410, (2015)

8. S. Kurra, N. H. Rahman, S. P. Regalla, A. K. Gupta, Comput. Science and Software Engin., (2015)

9. J. Belchior, Thèse de l'INSA Rennes, France, (2013)

10. C. Raju, S. Narayanan, Measurement, 78, 296-308, (2016) 